\title{
Nomological Network of Dispositional Mindfulness: Evidence from MIDUS-II and MIDUS-III
}

\author{
Min-Sun Kim ${ }^{1}$, Atsushi Oshio ${ }^{2}$, Eun-Joo Kim ${ }^{3}$, Satoshi Akutsu ${ }^{4} \&$ Ayano Yamaguchi ${ }^{5}$ \\ ${ }^{1}$ Department of Communicology, University of Hawaii at Manoa, Honolulu, Hawaii, 96822, USA \\ ${ }^{2}$ Faculty of Letters, Arts and Sciences, Waseda University, 1-24-1 Toyama, Shinjuku, Tokyo, 162-8644, Japan \\ ${ }^{3}$ The Graduate School of Education, Yonsei University, Shinchon-dong, Seodaemun-gu, Seoul, 120-749, South \\ Korea \\ ${ }^{4}$ School of International Corporate Strategy (ICS), Hitotsubashi University, 2-1-2 Hitotsubashi, Chiyoda, Tokyo, \\ 101-8439, Japan \\ ${ }^{5}$ College of Community and Human Services, Rikkyo University, 1-2-26 Kitano, Niiza-shi, Saitama, 352-8558, \\ Japan
}

Correspondence: Min-Sun Kim, Department of Communicology, University of Hawaii at Manoa, Honolulu, Hawaii, 96822, USA.

Received: May 9, 2019

Accepted: July 26, 2021

Online Published: August 10, 2021

doi:10.5539/ijps.v13n3p44

URL: https://doi.org/10.5539/ijps.v13n3p44

\begin{abstract}
While dispositional mindfulness is a popular construct in the field of positive psychology, its nomological network in the context of health and well-being is not well established. Our study addresses this limitation by examining the relationship between dispositional mindfulness and various health-related psychological constructs, including personality, social well-being, and affective states. Data for this study were gathered from the national longitudinal studies of health and well-being called Midlife in the United States (MIDUS-II and MIDUS-III). The nomological network analysis of dispositional mindfulness showed positive associations with both religiosity and overall well-being measures (e.g., Social Well-Being, Sympathy, Optimism, and Generativity) and negative associations with maladaptive tendencies (e.g., Pessimism, Aggression, Neuroticism, and Personal Constraints). Finally, test-retest validity was positively verified by significant correlations among the variables, spanning over ten years. Articulating a nomological network of dispositional mindfulness has important implications for future research and practice.
\end{abstract}

Keywords: dispositional mindfulness, nomological network, MIDUS, positive emotion

\section{Introduction}

The concept of mindfulness (i.e., the nonjudgmental awareness of one's internal or external environment) has been a core component in Buddhist meditative traditions (Brown, Ryan, \& Crosswell, 2007). Ven. Analayo, in his book called Satipattinata: The direct path to realization (2003), described mindfulness as seeing things just as they are, unadulterated by habitual reactions and projections. There has been significant growth in mindfulness research in the last 30 years or so, spanning fields as diverse as religious studies, neuroscience, clinical and positive psychology (Williams \& Kabat-Zinn, 2011). Mindfulness or its lack thereof is relevant to a diverse range of psychopathological and health-related outcomes as well. The potential benefits of mindfulness-based interventions have garnered the attention of researchers and clinical practitioners encompassing psychology and neuroscience (Chiesa \& Serretti, 2011).

Recent studies have examined the measurement of mindfulness and how it may influence and interact with cognition, emotion, interpersonal behavior, and neural structure and functioning (Davis \& Hayes, 2011). Interventions such as mindfulness-based cognitive therapy and stress management have become increasingly widespread. Further, as cultivating mindfulness is considered to be fundamental to the Buddhist path to "enlightenment" or "awakening" (Gethin, 2011), it has become progressively more important to establish a clear conceptual and operational definition of mindfulness.

Among different conceptual definitions of mindfulness, past research has focused on dispositional mindfulness, which refers to the general cross-situational frequency of mindful states over time (Kiselica, Rojas, Bornovalova, \& Dube, 
2015). Despite a wealth of research, the field of mindfulness remains in its adolescence. For example, although many studies have examined this construct in relation to various outcomes of interest, the systematic investigation of the nomological network of dispositional mindfulness is lacking. Nomological networks specify patterns of relations among constructs (Cronbach \& Meehl, 1955). Individual studies have frequently reported associations of dispositional mindfulness with specific trait and state factors. However, research has not explored the nomological network of dispositional mindfulness across various self-report measures on a scientific level. It appears that no study has simultaneously assessed convergent and discriminant relationships of dispositional mindfulness with other potentially related psychological constructs.

Endeavors to define and measure mindfulness have not been without controversy. The research has exposed significant disagreements, specifically about where and how a "true" understanding of mindfulness is to be found (Brown et al., 2007). Thus, there is a clear need for research that comprehensively establishes the convergent and discriminant validity of dispositional mindfulness. As a nomological network of dispositional mindfulness is not well established, the current study addresses this limitation by examining the relationships of dispositional mindfulness with various widely used self-reported psychological measures that have implications for health and well-being. Specifically, this study seeks to establish relationships of dispositional mindfulness with a variety of personality, affective (e.g., positive affect, negative affect, perceived stress), psychopathological, and other psychological variables. To establish the nomological network surrounding dispositional mindfulness, we used samples from the United States spanning two different points in time (about ten years apart), using MIDUS-II and MIDUS-III datasets. Because the groups represent two time periods, consistency across samples would increase confidence that the results are not merely local phenomena.

\section{Background of Mindfulness Research}

Mindfulness, which can be broadly understood as (1) the ongoing monitoring of present-moment experience (2) with an orientation of acceptance (Lindsay \& Crosswell, 2016), has generated a great deal of research in academic and applied psychology. According to Brown et al. (2007), mindfulness is thought to have been primarily developed from Buddhist traditions and several other philosophical and psychological traditions (e.g., ancient Greek philosophy, existentialism, transcendentalism, humanism, and naturalism). An early definition of mindfulness that continues to be useful and widely accepted among clinicians and researchers was established by Kabat-Zinn (1994), who defined mindfulness as intentional, nonjudgmental attention. More recently, Bishop et al. (2004) proposed a two-factor model of mindfulness composed of self-regulation of attention to maintain focus on the present experience and a purposeful orientation toward the present moment that includes non-striving. Therefore, of particular relevance to both the conceptualization and operationalization of mindfulness is the "non-judgment" or "receptive awareness or acceptance" as a path toward a centered and integrated way of being.

In general, mindfulness includes awareness and openness to the present moment. Langer and Moldoveanu (2000) extended the definition of mindfulness to include an environmental and problem-solving approach, presenting individuals with enhanced sensitivity to all of their available options. Mindfulness describes a quality of awareness that potentiates or creates the fertile conditions necessary for more integrated self-regulation. Currently, there are two main narratives of mindfulness. One is that of Buddhist meditative traditions and is often described as paying attention in a particular way, purposefully, in the present moment, and nonjudgmentally (Kabat-Zinn, 1994). Recent studies investigating mindfulness and various meditative techniques have shown great promise for clinical applications as well, especially in the area of stress reduction and the treatment of various mental health disorders (Keng, Smoski, \& Robins, 2011) as well as in the state of self-esteem (Pepping, O'Donovan, \& Davis, 2013).

The Buddhist narrative is rooted in the primarily introspective approach to knowledge found in India at the time of Gautama the Buddha approximately 2,500 years ago (Analayo, 2003). This narrative attributes the cause of human suffering to the ignorance of the moment-by-moment construction of a sense of ownership of experience in the mind and the dissatisfaction that arises from resultant craving and aversion. In other words, desire and ignorance are said to lie at the root of all suffering in this world. The Buddhist explanation for suffering invokes concepts of craving, aversion, and attachment. The cultivation of mindfulness is one of the elements of a systematic eightfold path claimed to have been put forward by the historical Buddha to escape from the cycle of ignorance and suffering (Analayo, 2003). Recognizing that Buddhism, medicine, and psychology share the common goal of reducing suffering has helped pave the way for introducing Buddhist mindfulness training exercises into Western medicine and psychotherapeutic programs (Carmody, Baer, Lykins, \& Olendzki, 2009).

The other narrative of mindfulness is based on contemporary cognitive science and is described as a cognitive style involving the moment-to-moment self-regulation of one's attention and an accepting and open engagement with one's environment (Hart, Ivtzan, \& Hart, 2013). Although research on mindfulness often focuses on these contemporary 
interests, it is preceded by the rich "inner science" (Cabezon, 2003) developed over many centuries in the Buddhist traditions. Wallace (2003) suggests a deep complementarity between Western scientific and Buddhist contemplative approaches to the study of the mind and behavior. The methods employed by each approach differ, as one is experimental, and the other is experiential. Still, the refinement of attention cultivated in Buddhist contemplative practices has made it a powerful tool for the direct observation of the mind and behavior. In this sense, Buddhism represents a mode of inquiry bridging rigorous logical analysis (as in philosophy) and empirical investigation (as in science) (Wallace, 2003).

State mindfulness has been conceptualized as a state practiced in mindfulness meditation (e.g., Lau et al., 2006) and as a trait of one's predisposition to be mindful in daily life (e.g., Baer, Smith, Hopkins, Krietemeyer, \& Toney, 2006). Measures of trait or dispositional mindfulness typically concern the general cross-situational frequency of mindful states over time. A study by Kiken, Garland, Bluth, Palsson and Gaylord (2015) found that heightening state mindfulness in meditation practice over time increases trait mindfulness, even though individuals' trajectories of change may vary. Most measures of mindfulness focus on one's predisposition to being mindful in daily life rather than the particular mindful state at the time of measurement. Studies found that dispositional mindfulness has positive relationships with working memory and sustained attention (Ruocco \& Wonders, 2013) and negative relationships with perceived stress and stress-related symptoms (Roberts \& Danoff-Burg, 2010). Mindfulness has also been found to be positively related to psychological well-being (Brown et al., 2007) and inversely associated with a wide range of problematic psychological outcomes, including anxiety and depression (Roemer et al., 2009) and general distress in life (Masuda \& Tully, 2012).

\section{The Present Study}

The present investigation examines the nomological network of dispositional mindfulness in the theoretical and empirical relations with other constructs. Exploring a theory's nomological network helps establish construct validity. Aside from addressing validity issues, our current research will also help enhance understanding of how mindfulness fits into the nomological network of other established indices of attention. Specifically, the present study examines both convergent and discriminant construct validity evidence for a commonly used self-report measure of dispositional mindfulness. In doing so, mindfulness will be placed within the broader nomological network related to individual-level psychological variables associated with health and well-being. Also, preliminary explanations will be presented regarding how mindfulness converges with and discriminates from existing constructs in the field of psychology. Whether dispositional mindfulness predicts theoretically expected outcomes is a key issue concerning its construct validity and research and clinical value.

Our study examines whether trait (dispositional) mindfulness is associated positively or negatively with various traits in cognitive, affective, and mental/physical health domains. Elucidating whether individual differences in mindfulness are related to well-established psychological constructs can inform our understanding of the value of sustained mindful states. Our goal is to investigate whether a self-report measure of dispositional mindfulness is related to a broad range of health-related behavioral and psychological traits in theoretically expected directions. Based on past literature, we predicted that dispositional mindfulness would be positively associated with adaptive psychological functioning and negatively associated with maladaptive psychological functioning. Creating ways to assess and validate the construct of dispositional mindfulness is essential for designing corresponding interventions focused on health and well-being.

\section{Methods}

\subsection{Participant Selection}

Participants were part of a national longitudinal study of health and well-being funded by the National Institute on Aging called Midlife in the United States (MIDUS). MIDUS was initiated as MIDUS-I in 1995 with a survey of approximately 7,000 English-speaking adults of both sexes between the ages of 25 and 74 years. As a follow-up study, MIDUS-II was conducted approximately ten years later using the same respondents, with data collected from 2004 to 2006 and a mortality-adjusted response rate of $75 \%$. MIDUS-II respondents were aged 35 to 86 . Data collection largely repeated baseline assessments (i.e., phone interview and extensive self-administered questionnaire), with additional questions in selected areas (e.g., cognitive functioning, optimism and coping, stressful life events, and caregiving). Overall, complete data were collected from nearly 5,900 individuals.

MIDUS-III was then conducted in 2013 and 2014. Participants were assessed through phone interviews and self-administered questionnaires. The data focused on behavioral, psychological, and social factors as well as physical and mental health. In our study, we used the MIDUS-II and MIDUS-III data sets. Both these rounds of the MIDUS survey included all of the following scales and response options. 


\subsection{Measures}

Mindfulness: Dispositional mindfulness was measured by the MIDUS-II Mindfulness Scale, based on Langer and Moldoveanu's (2000) conception of mindfulness. Their socio-cognitive approach to dispositional mindfulness encompasses novelty seeking, novelty producing, engagement, and flexibility for more consistent usage of mindfulness theory within social contexts. The scale was developed as a part of the "subjective religiosity" component of the survey (Einolf, 2013) and has been shown to have high reliability ( $\alpha=.94$; Sesker, Suilleabhain, Howard, $\&$ Hughes, 2016). The scale includes nine items in a self-administered questionnaire that presents the item prompt, "Because of your religion or spirituality, do you try to be:" Sample items include "more engaged in the present moment" and "more likely to perceive things in new ways." Participants responded using a Likert-type scale ranging from (1) Strongly agree to (5) Strongly disagree.

Life Satisfaction: Five items were measured based on Prenda and Lachman's (2001) Life Satisfaction Scale. The five items include overall life, work, health, relationship with spouse/partner, and relationship with children. Each item was coded from ( 0 ) the worst possible to (10) the best possible ( $\alpha=.63$ to .68).

Health Locus of Control: Health Locus of Control (Self) was measured by four items, including "Keeping healthy depends on things that I can do" $(\alpha=.74)$. Health Locus of Control (Others) was measured by the two items, including: "When I am sick, getting better is in the doctor's hands" $(\alpha=.11$ to .24$)$. Responses were measured on a 7-point scale ranging from (1) strongly agree to (7) strongly disagree.

Psychological Well-Being: The six dimensions of Psychological Well-Being (Positive Relations with Others: $\alpha=.58$, Self-Acceptance: $\alpha=.59$, Autonomy: $\alpha=.48$, Personal Growth: $\alpha=.55$, Environmental Mastery: $\alpha=.52$, Purpose in Life: $\alpha=.36$ ) were generated from the multiple theoretical accounts of positive functioning. In the initial validation study (Ryff, 1989), each dimension was operationalized with a 20-item scale that showed high internal consistency and test-retest reliability, as well as convergent and discriminant validity with other measures. To accommodate the time and cost restrictions of the MIDUS national survey, only 3 of the original 20 items were chosen to measure each construct. The shortened scales correlated from .70 to .89 with the 20 -item parent scales (Ryff, 1989). Responses ranged from (1) strongly agree to (7) strongly disagree.

Sense of Control: The Sense of Control Scale comprises two subscales: Personal Mastery and Perceived Constraints. Personal Mastery assesses how capable a person feels of accomplishing his/her goals. In contrast, Perceived Constraints measures a person's perception of the number of uncontrollable obstacles standing in the way of his/her goals. The Personal Mastery subscale contains four items, and the Perceived Constraints subscale comprises eight items. Both subscales contain items from Pearlin and Schooler's (1978) Mastery Scale and items created by Lachman and Weaver (1998). A sample Personal Mastery item is: "I can do just about anything I really set my mind to." Perceived Constraints items include: "There is little I can do to change the important things in my life." Participants responded on a Likert-type scale of (1) Strongly agree to (7) Strongly disagree. It has been determined that the scale is valid (Lachman \& Weaver, 1998) and reliable $(\alpha=.73$ to .87$)$.

Self-Esteem: Self-esteem was assessed by seven items proposed by Rosenberg (1965). The items include: "I take a positive attitude toward myself," "On the whole, I am satisfied with myself." The responses were coded on a scale of (1) Strongly agree to (7) Strongly disagree $(\alpha=.76)$.

Self-Construal: This scale consisted of Interdependence ( $\alpha=31$ to .38$)$ and Independence $(\alpha=.17$ to .31$)$ subscales. Based on Singelis' (1994) self-construal scale, three items measuring Interdependence include: "My happiness depends on the happiness of those around me," Three items measuring Independence include: "I act in the same way no matter who I am with." Responses were coded on a scale of (1) Strongly agree to (7) Strongly disagree.

Big Five Personality Traits: The Big Five is the most widely used model of personality in the research literature. Rossi's (2001) scale of personality traits included Extraversion (energetic, approach-oriented), Agreeableness (prosocial tendency towards others), Conscientiousness (impulse control and attention to detail), Neuroticism (general tendency to experience negative emotions and distress), and Openness (open-mindedness and originality). These personality traits were measured using self-descriptive adjectives. Participants were asked to rate how well the adjectives described them, with responses ranging from (1) A lot to (4) Not at all. The personality trait measures have been shown to be reliable (Extraversion items, $\alpha=.76$; Agreeableness items, $\alpha=.80$; Conscientiousness items, $\alpha=.68$; Neuroticism items, $\alpha=.74$; Openness items, $\alpha=.77$; Staudinger, Fleeson, \& Bates, 1999).

Multidimensional Personality: This measure comprises three individual scales: Positive Emotionality, Negative Emotionality, and Constraint. Within the Positive Emotionality scale are four sub-scales: Well-Being, Social Potency, Achievement, and Social Closeness. The Well-Being sub-scale comprised three items. A sample item is: "I usually find ways to liven up my day." The Social Potency sub-scale consisted of four items. A sample item is: "On 
most social occasions I like to have someone else take the lead." Four items measured the Achievement sub-scale, including: "I often go on working on a problem long after others would have given up." The Social Closeness sub-scale included four items. A sample item is: "I usually like to spend my leisure time with friends rather than alone."

The second scale, Negative Emotionality, comprises three sub-scales: Stress Reactivity, Aggression, and Alienation. A sample item for the Stress Reactivity sub-scale (3 items) is: "My mood often goes up and down." Four items measured the Aggression sub-scale. A sample item is: "When I get angry, I am often ready to hit someone." The Alienation sub-scale was measured by three items, including "People often try to take advantage of me."

Finally, the third scale, Constraint, was composed of three sub-scales: Control, Traditionalism, and Harm Avoidance. The Control sub-scale was measured by three items, including "When faced with a decision, I usually take time to consider and weigh all options." The Traditionalism sub-scale was also measured by three items, including "I am opposed to more censorship of books and movies because it would go against free speech." The third sub-scale, Harm Avoidance, contained items such as, "It might be fun and exciting to experience an earthquake" (Patrick, Curtin, \& Tellegen, 2002; Tellegen, 1985). Alphas ranged from .56 to .74 across all subscales measuring Multidimensional Personality.

Life Orientation: This construct consisted of two components (Optimism and Pessimism) which were measured on a scale by Scheier and Carver (1985). Three items measured optimism, including: "In uncertain times, I usually expect the best." Three items also measure pessimism, including: "If something can go wrong for me, it will." Responses ranged from (1) Strongly agree to (5) Strongly disagree. Alphas ranged from .70 to .80.

Social Well-Being: This comprised five factors and was measured on a scale by Keyes (1995). The first factor, Meaningfulness of Society, was measured by two items, including "The world is too complex for me." The second factor, Social Integration, was measured by three items, including "I don't feel I belong to anything I'd call a community." Acceptance of Others, the third factor, was measured by three items, including "People who do a favor expect nothing in return." The fourth factor, Social Contribution, was assessed by three items, including "I have something valuable to give to the world." Finally, Social Actualization was measured by three items, including "The world is becoming a better place for everyone." The items were coded on a Likert scale of (1) Strongly agree to (7) Strongly disagree. Alphas ranged from .39 to .77.

Sympathy: The Sympathy scale comprised four items and is based on a scale by Uchida and Kitayama (2001), with responses ranging from (1) Strongly agree to (7) Strongly disagree. The items included, "Even when things are going well for me, I can't be happy if I have a friend who is in trouble." Alphas ranged from .46 to .50 .

Generativity: This is one of the key concepts of development in middle adulthood. The items of this scale were based on McAdams and de St. Aubin's (1992) Loyola Generativity Scale (LGS). The six items include: "Others would say that you have made unique contributions to society" and "You have important skills you can pass along to others." Responses were coded on a scale of (1) A lot to (4) Not at all. $(\alpha=.85$.)

Friend Support and Strain: This scale was based on a study by Schuster, Kessler, \& Aseltine (1990). Friend Support was assessed by four items, including "How much do your friends really care about you?" It was coded on a scale of (1) A lot to (4) Not at all. Friend Strain was measured by four items, including "How often do your friends make too many demands on you?" Responses were coded on a scale of (1) Often to (4) Never. A Friend Affectual Solidarity score was obtained based on an eight-item scale combining the four "Friend Support" items and the four "Friend Strain" items. Alphas ranged from .78 to .80 .

Religiosity: This scale was composed of seven factors. The first factor, Spirituality, was assessed by two items, "How spiritual are you?" and "How important is spirituality in your life?" Responses were coded on a scale of (1) Very to (4) Not at all. The second factor, Religious Identification, used seven items to assess religious identification, including "How religious are you?" Participants responded on a Likert-type scale of (1) Very to (4) Not at all. The third factor, Private Religious Practices, was assessed by three items including: "How often do you": "Pray in private?" Responses were coded on a scale of: (1) Once a day or more to (6) Never. The fourth factor, Religious Support, was measured by four items, including "If you were ill, how much would people in your congregation help you out?" Responses were coded on a scale of (1) A great deal to (4) None. Alphas ranged from .46 to .50. The fifth factor, Religious/Spiritual Coping A, was measured by two items based on Garfield, Ryff, and Singer's (2001) study. A sample item is, "When you have decisions to make in your daily life, how often do you ask yourself what your religious or spiritual beliefs suggest you should do?" Responses were coded on a scale of (1) Often to (4) Never. The sixth factor, Religious/Spiritual Coping B, was assessed by six items from the Fetzer Institute/National Institute on Aging Working Group's Multidimensional Measurement of Religiousness/ Spirituality for Use in Health Research (1999). A sample item is, "I try to make sense of the situation and decide what to do without relying on God." The responses were coded 
on a scale of (1) A great deal to (4) None. Finally, the seventh factor, Daily Spiritual Experiences, was quantified by five items, e.g., "On a daily basis, how often do you experience the following": "A feeling of deep inner peace or harmony" and four other items. Responses were coded on a scale of (1) Often to (4) Never. Alphas ranged from .90 to .92 .

\section{Results}

\subsection{Preliminary Analyses}

As preliminary analyses, we investigated the differences in means between variables used in MIDUS-II and MIDUS-III. T-tests revealed that, with the large sample sizes, there were several significant mean differences of variables between MIDUS-II and MIDUS-III. In Cohen's $d$ effect size, values are considered as small (0.2), medium $(0.5)$, and large $(0.8)$ when interpreting the effect size of the mean differences. In this study, there were many mean differences between MIDUS-II and MIDUS-III, but with only small effect sizes. Among the variables, only two revealed a Cohen's $d$ effect size of over .20 (Social Actualization and Strain from Friends). As the participants aged, the mean value for Social Actualization decreased (from 12.88 to 11.68), and the mean value for Strain from Friends also decreased (from 1.83 to 1.72 ).

\subsection{Main Analyses}

First, Pearson product-moment correlation coefficients were calculated among the variables (see Table 1). Bivariate correlations between dispositional mindfulness and other psychological traits were then examined. The results were consistent across the two time points of MIDUS-II and MIDUS-III; that is, the z-scores (for comparing the magnitude of differences in correlation coefficients) were not significant (see Table 1).

Of the numerous psychological traits examined, Religiosity was identified as the strongest correlate of mindfulness. Consistent with previous research, evidence of convergent validity was observed, with moderate- sized positive correlations ( $r=.39$ to $r=.52, p<.001$ for MIDUS-II; $r=.42$ to $r=.52, p<.001$ for MIDUS-III) between Mindfulness and the Religiosity sub-scales of Spirituality, Religious Identification, Private Religious Practices, Religious/Spiritual Coping, and Daily Spiritual Experience, with the exception of Religious Support $(r=.25, p<.001$ for MIDUS-II; $r=.20, p<.001$ for MIDUS-III).

Positive associations were observed between the Mindfulness scale and Overall Well-Being measures, consistent with previous findings. The Mindfulness scale was determined to be positively associated with two of the Social Well-Being measures (Social Integration and Social Contribution), as well as one measure of Psychological Well-Being (Personal Growth). The Personal Growth measure was found to be the strongest correlate of Mindfulness $(r=.23, p<.001$ for MIDUS-II; $r=.24$ for MIDUS-III, $p<.001)$ among the six sub-factors.

The Mindfulness scale showed moderately sized correlations in the expected positive direction with four sub-scales of the Big Five Personality traits. Of the Big Five Personality traits, agreeableness was identified as the strongest correlate of mindfulness $(r=.34, p<.001$ for both MIDUS-II and MIDUS-III), followed by Extraversion $(r=.22, p$ $<.001$ for MIDUS-II; $r=.25, p<.001$ for MIDUS-III). As expected, Mindfulness was correlated negatively (though weakly) with Neuroticism ( $r=-.08, p<.001$ for MIDUS-II; $r=-.09, p<.001$ for MIDUS-III). With regard to Multidimensional Personality, the Mindfulness score was positively correlated with the three sub-scales of Well-being $(r=.25, p<.001$ for MIDUS-II; $r=.26, p<.001$ for MIDUS-III), Social Closeness $(r=.22, p<.001$ for MIDUS-II; $r=.26, p<.001$ for MIDUS-III), and Traditionalism ( $r=.20, p<.001$ for MIDUS-II; $r=.19, p<.001$ for MIDUS-III), while being negatively correlated with Aggression ( $r=-.15, p<.001$ for MIDUS-II; $r=-.16, p<.001$ for MIDUS-III) and Reactivity ( $r=-.09, p<.001$ for both MIDUS-II and MIDUS-III datasets). Alienation was the weakest and sole non-significant correlate. 
Table 1. Correlations between Mindfulness and Other Variables using MIDUS II and MIDUS III Datasets

\begin{tabular}{|c|c|c|c|c|c|c|c|c|c|c|}
\hline & \multicolumn{6}{|c|}{ Mindfulness } & \multirow[b]{3}{*}{ z-value } & \multirow{2}{*}{\multicolumn{3}{|c|}{$\begin{array}{l}\text { MIDUS II and III } \\
\text { test-retest correlation }\end{array}$}} \\
\hline & \multicolumn{3}{|c|}{ MIDUS II } & \multicolumn{3}{|c|}{ MIDUS III } & & & & \\
\hline & $r$ & $p$ & $n$ & $r$ & $p$ & $n$ & & $r$ & $p$ & $n$ \\
\hline 0 . Mindfulness & - & - & - & - & - & - & - & .576 & $<.001$ & 2468 \\
\hline 1. Life Satisfaction (6-item version) & .087 & $<.001$ & 3967 & $.076<$ & $<.001$ & 2647 & 0.44 n.s. & .606 & $<.001$ & 2565 \\
\hline \multicolumn{11}{|l|}{ 2. Health Locus of Control } \\
\hline (1) Self & .195 & $<.001$ & 3945 & $.183<$ & $<.001$ & 2632 & 0.49 n.s. & .442 & $<.001$ & 2534 \\
\hline (2) Others & .044 & $<.005$ & 3944 & .020 & n.s. & 2630 & 0.95 n.s. & .399 & $<.001$ & 2532 \\
\hline \multicolumn{11}{|l|}{ 3. Psychological Well-Being (3-item version) } \\
\hline (1) Autonomy & .086 & $<.001$ & 3959 & .093 & $<.001$ & 2642 & -0.28 n.s. & .491 & $<.001$ & 2555 \\
\hline (2) Environmental Mastery & .087 & $<.001$ & 3955 & .088 & $<.001$ & 2646 & -0.04 n.s. & .489 & $<.001$ & 2557 \\
\hline (3) Personal Growth & .242 & $<.001$ & 3959 & .225 & $<.001$ & 2646 & 0.72 n.s. & .539 & $<.001$ & 2559 \\
\hline (4) Positive Relations with Others & .197 & $<.001$ & 3959 & .181 & $<.001$ & 2646 & 0.66 n.s. & .589 & $<.001$ & 2559 \\
\hline (5) Purpose in Life & .044 & $<.005$ & 3959 & .052 & $<.007$ & 2645 & -0.32 n.s. & .520 & $<.001$ & 2558 \\
\hline (6) Self-Acceptance & .136 & $<.001$ & 3958 & .142 & $<.001$ & 2646 & -.24 n.s. & .631 & $<.001$ & 2558 \\
\hline \multicolumn{11}{|l|}{ 4. Sense of Control } \\
\hline (1) Personal Mastery & .119 & $<.001$ & 3946 & .102 & $<.001$ & 2635 & 0.68 n.s. & .524 & $<.001$ & 2537 \\
\hline (2) Perceived Constraints & -.065 & $<.001$ & 3948 & -.098 & $<.001$ & 2635 & 1.32 n.s. & .605 & $<.001$ & 2538 \\
\hline (3) Sense of Control (Mastery + Constraints) & .092 & $<.001$ & 3946 & .112 & $<.001$ & 2635 & -0.80 n.s. & .642 & $<.001$ & 2537 \\
\hline 5. Self-Esteem & .087 & $<.001$ & 3946 & .080 & $<.001$ & 2635 & 0.28 n.s. & .648 & $<.001$ & 2536 \\
\hline \multicolumn{11}{|l|}{ 6. Self-construal } \\
\hline (1) Interdependence & .054 & $<.001$ & 3945 & .053 & $<.0062$ & 2634 & 0.04 n.s. & .434 & $<.001$ & 2536 \\
\hline (2) Independence & .182 & $<.001$ & 3945 & .173 & $<.0012$ & 2634 & 0.37 n.s. & .454 & $<.001$ & 2536 \\
\hline \multicolumn{11}{|l|}{ 7. Big Five personality traits } \\
\hline (1) Agreeableness & .343 & $<.001$ & 3941 & .336 & $<.001$ & 2638 & $8 \quad 0.31$ n.s. & .652 & $<.001$ & 2543 \\
\hline (2) Extraversion & .254 & $<.001$ & 3942 & .219 & $<.001$ & 2637 & $7 \quad 1.47$ n.s. & .716 & $<.001$ & 2542 \\
\hline (3) Neuroticism & -.081 & $<.001$ & 3940 & -.086 & $<.001$ & 2637 & $7 \quad 0.20$ n.s. & .660 & $<.001$ & 2538 \\
\hline (4) Conscientiousness & .114 & $<.001$ & 3941 & .081 & $<.001$ & 2639 & $9 \quad 1.32$ n.s. & .619 & $<.001$ & 2543 \\
\hline (5) Openness & .205 & $<.001$ & 3907 & .179 & $<.001$ & 2635 & $5 \quad 1.07$ n.s. & .707 & $<.001$ & 2523 \\
\hline \multicolumn{11}{|l|}{ 8. Multidimensional Personality } \\
\hline (1) Well-Being & .249 & $<.001$ & 3947 & .253 & $<.001$ & 2633 & $3-0.17$ n.s. & .627 & $<.001$ & 2536 \\
\hline (2) Social Potency & .096 & $<.001$ & 3948 & .092 & $<.001$ & 2634 & $4 \quad 0.16$ n.s. & .703 & $<.001$ & 2538 \\
\hline (3) Achievement & .163 & $<.001$ & 3948 & .140 & $<.001$ & 2633 & $3 \quad 0.94$ n.s. & .642 & $<.001$ & 2536 \\
\hline (4) Social Closeness & .223 & $<.001$ & 3949 & .260 & $<.001$ & 2634 & $4 \quad-1.56$ n.s. & .639 & $<.001$ & 2538 \\
\hline (5) Reactivity & -.089 & $<.001$ & 3945 & -.089 & $<.001$ & 2633 & $3 \quad 0.00$ n.s. & .616 & $<.001$ & 2533 \\
\hline (6) Aggression & -.157 & $<.001$ & 3949 & -.152 & $<.001$ & 2635 & $5 \quad-0.20$ n.s. & .580 & $<.001$ & 2538 \\
\hline (7) Alienation & .010 & n.s. & 3947 & -.008 & n.s. & 2631 & $1 \quad 0.71$ n.s. & .616 & $<.001$ & 2534 \\
\hline (8) Control & .177 & $<.001$ & 3947 & .148 & $<.001$ & 2632 & 21.18 n.s. & .564 & $<.001$ & 2534 \\
\hline (9) Traditionalism & .203 & $<.001$ & 3934 & .194 & $<.001$ & 2625 & $5 \quad 0.37$ n.s. & .689 & $<.001$ & 2522 \\
\hline (10) Harm Avoidance & .055 & $<.001$ & 3951 & .097 & $<.001$ & 2635 & $5 \quad-1.68$ n.s. & .637 & $<.001$ & 2540 \\
\hline \multicolumn{11}{|l|}{ 9. Life Orientation } \\
\hline (1) Optimism & .219 & $<.001$ & 3951 & .243 & $<.001$ & 2634 & $4 \quad-1.01$ n.s. & .596 & $<.001$ & 2537 \\
\hline (2) Pessimism & -.080 & $<.001$ & 3951 & -.123 & $<.001$ & 2634 & $4 \quad 1.73$ n.s. & .626 & $<.001$ & 2537 \\
\hline (3) Overall: Optimism + Pessimism & .165 & $<.001$ & 3951 & .204 & $<.001$ & 2634 & $4 \quad-1.60$ n.s. & .689 & $<.001$ & 2537 \\
\hline \multicolumn{11}{|l|}{ 10. Social Well-Being } \\
\hline (1) Meaningfulness of Society & .001 & n.s. & 3942 & .030 & n.s. & 2614 & $4 \quad-1.15$ n.s. & .545 & $<.001$ & 2491 \\
\hline (2) Social Integration & .261 & $<.001$ & 3944 & .263 & $<.001$ & 2615 & $5 \quad-0.09$ n.s. & .602 & $<.001$ & 2493 \\
\hline (3) Acceptance of Others & .136 & $<.001$ & 3944 & .126 & $<.001$ & 2615 & $5 \quad 0.40$ n.s. & .490 & $<.001$ & 2493 \\
\hline (4) Social Contribution & .210 & $<.001$ & 3943 & .244 & $<.001$ & 2613 & $3 \quad-1.42$ n.s. & .610 & $<.001$ & 2491 \\
\hline (5) Social Actualization & .066 & $<.001$ & 3943 & .051 & $<.009$ & 2614 & $4 \quad 0.60$ n.s. & .482 & $<.001$ & 2491 \\
\hline 11. Sympathy scale & .261 & $<.001$ & 3920 & .262 & $<.001$ & 2609 & $9 \quad-0.04$ n.s. & .524 & $<.001$ & 2468 \\
\hline 12. Generativity & .272 & $<.001$ & 3917 & .264 & $<.001$ & 2596 & $6 \quad 0.34$ n.s. & .637 & $<.001$ & 2469 \\
\hline \multicolumn{11}{|l|}{ 13. Friendship } \\
\hline (1) Support from Friends & .232 & $<.001$ & 3941 & .252 & $<.001$ & 2625 & $5 \quad-0.84$ n.s. & .525 & $<.001$ & 2496 \\
\hline (2) Strain from Friends & -.005 & n.s. & 3940 & -.048 & $<.014$ & 2622 & 21.71 n.s. & .428 & $<.001$ & 2491 \\
\hline
\end{tabular}


(3) Friendship Affectual Solidarity

14. Religiosity

\section{(1) Spirituality}

(2) Religious Identification

(3) Private Religious Practices

(4) Religious Support

(5) Religious/Spiritual Coping A

(6) Religious/Spiritual Coping B

(7) Daily Spiritual Experience

\begin{tabular}{rllllllllll}
.178 & $<.001$ & 3941 & .208 & $<.001$ & 2626 & -1.24 n.s. & .505 & $<.001$ & 2497 \\
.513 & $<.001$ & 3953 & .522 & $<.001$ & 2630 & -0.49 n.s. & .715 & $<.001$ & 2501 \\
.394 & $<.001$ & 3954 & .416 & $<.001$ & 2637 & -1.05 n.s. & .849 & $<.001$ & 2505 \\
.462 & $<.001$ & 3948 & .484 & $<.001$ & 2633 & -1.13 n.s. & .801 & $<.001$ & 2500 \\
.246 & $<.001$ & 2393 & .198 & $<.001$ & 1563 & 1.55 n.s. & .469 & $<.001$ & 1301 \\
.480 & $<.001$ & 3945 & .488 & $<.001$ & 2638 & -0.42 n.s. & .738 & $<.001$ & 2493 \\
.506 & $<.001$ & 3942 & .496 & $<.001$ & 2633 & 0.53 n.s. & .731 & $<.001$ & 2480 \\
.516 & $<.001$ & 3949 & .494 & $<.001$ & 2655 & 1.18 n.s. & .637 & $<.001$ & 2476 \\
\hline
\end{tabular}

Note. Dark shaded correlation coefficients represent $r>.30$ and Light shaded correlation coefficints indicate $r>.20$.

Regarding relational dynamics, Friend Support $(r=.23, p<.001$ for MIDUS-II; $r=.25, p<.001$ for MIDUS-III) and Friend Affectual Solidarity ( $r=.18, p<.001$ for MIDUS-II; $r=.21, p<.001$ for MIDUS-III) were positively associated with Mindfulness as expected, while Friend Strain was not significantly associated with Mindfulness $(r=$ -.01 , n.s. for MIDUS-II; $r=-.05$, n.s. for MIDUS-III). With regard to Health Locus of Control (HLC), Self-HLC was moderately related to Mindfulness ( $r=.20, p<.001$ for MIDUS-II; $r=.18, p<.001$ for MIDUS-III). Regarding Sense of Control, there was a weak positive relationship between Personal Mastery and Mindfulness $(r=.12, p<.001$ for MIDUS-II; $r=.10, p<.001$ for MIDUS-III), whereas Perceived Constraints was a weak negative correlate of Mindfulness ( $r=-.07, p<.001$ for MIDUS-II; $r=-.10, p<.001$ for MIDUS-III).

In the case of Life Orientation, Mindfulness was positively associated with Optimism ( $r=.22, p<.001$ for MIDUS-II; $r=.24, p<.001$ for MIDUS-III), and negatively associated with Pessimism $(r=-.08, p<.001$ for MIDUS-II; $r=-.12$, $p<.001$ for MIDUS-III). Regarding the Self-Construal scale, Mindfulness had a stronger association with Independence $(r=.18, p<.001$ for MIDUS-II; $r=.17, p<.001$ for MIDUS-III) than with Interdependence ( $r=.05, p$ $<.001$ for MIDUS-II; $r=.05, p<.006$ for MIDUS-III). In further support of the convergent validity, the Mindfulness score was correlated positively with Sympathy $(r=.26$ for both data sets, $p<.001)$ and Generativity $(r=.26$ for MIDUS-II; $r=.27, p<.001$ for MIDUS-III). There was a weak positive correlation between Mindfulness and Self-Esteem $(r=.09$ for MIDUS-II; $r=.08, p<.001$ for MIDUS-III). Similarly, Life Satisfaction was positively associated with Mindfulness ( $r=.08, p<.001$ for MIDUS-II; $r=.07, p<.001$ for MIDUS-III).

\section{Discussion}

The present study aimed to clarify the convergent and divergent validity of dispositional mindfulness with health-related psychological and personality traits. The goal was to comprehensively assess the relationships between dispositional mindfulness and other well-established psychological constructs in the literature. In summary, bivariate correlations (displayed in Table 1) revealed that self-reported dispositional mindfulness was most strongly associated with the subscales of Religiosity, followed by Positive Emotionality, Well-Being, Sense of Control, Health Locus of Control (Self), and positive personality traits. Further, the Mindfulness scale was closely related to the Life Orientation sub-scale of Optimism and the Sympathy and Generativity scales but was negatively associated with Aggression and Neuroticism.

In our analyses, z-scores for comparing the size of correlations between MIDUS-II and MIDUS-III were all non-significant. Furthermore, agreement in both samples was quite high for the self-report measures of dispositional mindfulness. Specifically, the correlation results for dispositional mindfulness were relatively uniform across MIDUS-II and MIDUS-III samples, spanning almost ten years.

As expected, our results indicated that greater levels of mindful awareness were associated with a favorable outlook on life and more positive personality traits, with some correlations in the moderate to the strong range. These findings were consistent with previous research, which showed that higher levels of mindfulness were associated with greater well-being, positive affect, life satisfaction, vitality, optimism, autonomy, self-esteem, self-actualization, and competence. Furthermore, as expected, specific maladaptive orientations such as Pessimism, Aggression, Neuroticism, and Personal Constraints were negatively correlated with dispositional mindfulness.

Despite limitations in existing research on mindfulness, several key conclusions can be drawn from the consistent findings in our analyses. Our results are consistent with previous studies, which showed positive relationships with self-control, life satisfaction, agreeableness, objectivity, optimism, and pleasant affect (see Keng et al., 2011, for review). Our analyses also provide evidence that greater levels of mindful awareness correlate negatively with maladaptive functions such as aggression, neuroticism, depression, and perceived stress (see Brown \& Ryan, 2003, for review). Our results are consistent with these previous findings. 
Measures administered in MIDUS-II and MIDUS-III were shortened but reliable. Overall, the scale reliabilities of the measures were good, and the relationships between mindfulness and other variables were consistent with the existing literature on mindfulness. Furthermore, our study demonstrates that the relationships among the variables are highly stable over time by identifying similar relationships of dispositional mindfulness with other variables, using the two data sets spanning more than ten years. This evidence permits cross-validation of the dispositional mindfulness nomological network and reduces the likelihood of chance or sample-specific findings.

These findings should help establish mindfulness as a construct that has consistent relationships with other well-established psychological constructs. Based on our investigation of the nomological network, dispositional mindfulness is a construct that has associations with both adaptive and maladaptive psychological tendencies. It is particularly important to untangle this construct, as it has substantial implications for health-related interventions. Research could be undertaken to further elucidate the construct of dispositional mindfulness and ultimately lead to clinical research and focused interventions for psychopathologies and maladaptive behavior. Mindfulness is an increasingly crucial theoretical concept in psychology, as it is a state of mind that can be developed and enhanced through practices such as meditation.

\section{Limitations}

Our study is not without limitations. Firstly, most measurements that assess mindfulness focus on a general tendency to be mindful in daily life. However, the mindfulness items in the MIDUS studies were presented in a religious/spiritual context, which could have influenced the responses of non-religious participants. Additionally, the Mindfulness scale used in the MIDUS studies was a shortened version of the original scale developed by Bodner and Langer (2001) specifically for MIDUS-II and III. As Zimmerman (1995) noted, components of dispositional mindfulness may not be fully captured by any single specific operationalization because they take on different forms in different samples and contexts. At the scale level, future researchers might compare different scales of mindfulness across various contexts to establish the construct validity of the existing measures.

Secondly, most mindfulness measures consist of self-report surveys, as they are typically easy to administer (Falkenstrom, 2010). The scope of this study was limited to understanding dispositional mindfulness through such self-report measures. Previous research has suggested that there may be a lack of correspondence across measurement types. While self-reports of mindfulness are useful in assessing the mechanisms and outcomes of mindfulness-based therapies, future research might benefit from comparing self-report and behavioral mindfulness via multiple methods (e.g., interview, behavioral tasks, self-reports, observations) to minimize the issue of method variance.

Thirdly, this study focused on bivariate associations among variables involving dispositional mindfulness. A construct may play various roles (i.e., endogenous, exogenous, moderator, or mediator variables) in different conceptual models. Given the large number of variables involved, we did not propose a specific model. However, our study could identify future research opportunities focusing on specific models with moderators or mediators.

Lastly, the current study was based on a nonclinical population mainly composed of middle-aged individuals residing in the United States. So, caution should be exercised in generalizing to other populations. It would be essential to assess whether convergent and discriminant validity of dispositional mindfulness is observed in a clinical sample and samples from diverse cultural backgrounds. There is also a clear need to establish the content validity of the various measures of mindfulness among novice and experienced meditators with different ethnic backgrounds.

\section{Conclusion}

Our study provides a convergent validity test of a self-report measure of dispositional mindfulness along with an examination of its discriminant validity. While there has been tremendous growth in research involving mindfulness in the past 30 years, the field of mindfulness science is still maturing. Meditation and mindfulness practice in clinical interventions have been used to promote physical health, mental health, and psychological well-being for multiple populations. The literature agrees that mindfulness practice is an essential tool in improving mental health (Brown \& Ryan, 2003; Falkenstom, 2010; Keng et al., 2011). Furthermore, mindful awareness can be cultivated as an individual attribute, making it a good point of leverage for personal growth efforts and clinical interventions (Brown et al., 2007; Segal, Williams, \& Teasdale, 2018).

Research on the conceptualization and operationalization of mindfulness has generated debates about the meaning, assessment, development, and cultivation of this attribute. Efforts to refine and measure primary forms of mindfulness as a trait can contribute to developing theories and establishing empirical findings. We believe our study to be among the broadest analyses to date of the nomological network of dispositional mindfulness. A nomological network is a theoretical framework that represents the basic features of a construct, its observable manifestations, and the interrelationships among them (Cronbach \& Meehl, 1955). Articulating a nomological network of dispositional 
mindfulness is valuable for future research and practice as it enables the development of new measures and mindfulness interventions.

\section{Compliance with Ethical Standards}

Conflict of Interest: The authors declare that they have no conflict of interest.

Ethical Approval: All procedures performed in studies involving human participants were in accordance with the ethical standards of the institutional and/or national research committee and with the 1964 Helsinki declaration and its later amendments or comparable ethical standards.

Informed Consent: Informed consent was obtained from all individual participants included in the study.

\section{References}

Analayo, B. (2003). Satipattinata: The direct path to realization. Birmingham, UK: Windhorse.

Baer, R. A., Smith, G. T., Hopkins, J., Krietemeyer, J., \& Toney, L. (2006). Using self-report assessment methods to explore facets of mindfulness. Assessment, 13, 27-45. https://doi.org/10.1177/1073191105283504

Bishop, S. R., Lau, M., Shapiro, S., Carlson, L., Anderson, N. D., Carmody, J., \& Devins, G. (2004). Mindfulness: A proposed operational definition. Clinical Psychology: Science and Practice, 11(3), 230-241. https://doi.org/10.1093/clipsy.bph077

Bodner, T. E., \& Langer, E. J. (2001). Individual differences in mindfulness: the mindfulness/mindlessness scale. Paper presented at the 13th annual American Psychological Society Convention, Toronto. Ontario, Canada.

Brown, K. W., \& Ryan, R. M. (2003). The benefits of being present: Mindfulness and its role in psychological well-being. Journal of Personality and Social Psychology, 84, 822-848. https://doi.org/10.1037/0022-3514.84.4.822

Brown, K. W., Ryan, R. M., \& Creswell, J. D. (2007). Mindfulness: Theoretical Foundations and Evidence for its salutary Effects. Psychological Inquiry, 18, 211-237. https://doi.org/10.1080/10478400701598298

Cabezon, J. I. (2003). Buddhism and science: On the nature of the dialogue. In B. A. Wallace (Ed.), Buddhism and science: Breaking new ground (pp. 35-68). New York: Columbia University Press.

Carmody, J., Baer, R. A., Lykins, E. L., \& Olendzki, N. (2009). An empirical study of the mechanisms of mindfulness in a mindfulness-based stress reduction program. Journal of Clinical Psychology, 65, 613-626. https://doi.org/10.1002/jclp.20579

Chiesa, A., \& Serretti, A. (2011). Mindfulness-based interventions for chronic pain: A systematic review of the evidence. Journal of Alternative \& Complementary Medicine, 17, 83-93. https://doi.org/10.1089/acm.2009.0546

Cronbach, L. J., \& Meehl, P. C. (1955). Construct validity in psychological tests. Psychological Bulletin, 52, 281-302. https://doi.org/10.1037/h0040957

Davis, D. M., \& Hayes, J. A. (2011). What are the benefits of mindfulness? A practice review of psychotherapy-related research. Psychotherapy, 48(2), 198-208. https://doi.org/10.1037/a0022062

Einolf, C. J. (2013). Daily spiritual experiences and prosocial behavior. Social Indicators Research, 110, 71-87. https://doi.org/10.1007/s11205-011-9917-3

Falkenström, F. F. (2010). Studying mindfulness in experienced meditators: A quasi-experimental approach. Personality and Individual Differences, 48, 305-310. https://doi.org/10.1016/j.paid.2009.10.022

Garfield, A. M., Ryff, C. D., \& Singer, B. (2001). Religion and health: Probing the connections. Paper presented at the Poster presented at the 13th Annual Conference of the American Psychological Society.

Gethin, R. (2011). On some definitions of mindfulness. Contemporary Buddhism, 12, 263-279. https://doi.org/10.1080/14639947.2011.564843

Hart, R., Ivtzan, I., \& Hart, D. (2013). Mind the gap in mindfulness research: A comparative account of the leading schools of thought. Review of General Psychology, 17, 453-466. https://doi.org/10.1037/a0035212

Kabat-Zinn, J. (1994). Wherever you go, there you are: Mindfulness meditation in everyday life. London: Piatkus Google Scholar.

Keng, S. L., Smoski, M. J., \& Robins, C. J. (2011). Effects of mindfulness on psychological health: A review of empirical studies. Clinical Psychology Review, 31, 1041-1056. https://doi.org/10.1016/j.cpr.2011.04.006 
Keyes, C. L. M. (1995). The social side of psychological well-being (Doctoral Dissertation). Department of Sociology, University of Wisconsin, Madison.

Kiken, L. G., Garland, E. L., Bluth, K., Palsson, O. S., \& Gaylord, S. A. (2015). From a state to a trait: Trajectories of state mindfulness in meditation during intervention predict changes in trait mindfulness. Personality and Individual Differences, 81, 41-46. https://doi.org/10.1016/j.paid.2014.12.044

Kiselica, A. M., Rojas, E., Bornovalova, M. A., \& Dube, C. (2015). The nomological network of self-reported distress tolerance. Assessment, 22, 715-729. https://doi.org/10.1177/1073191114559407

Lachman, M. E., \& Weaver, S. L. (1998). The sense of control as a moderator of social class differences in health and well-being. Journal of Personality and Social Psychology, 74, 763-773. https://doi.org/10.1037/0022-3514.74.3.763

Langer, E. J., \& Moldoveanu, M. (2000). The construct of mindfulness. Journal of Social Issues, 56, 1-9. https://doi.org/10.1111/0022-4537.00148

Lau, M. A., Bishop, S. R., Segal, Z. V., Buis, T., Anderson, N. D., Carlson, L. E., Devins, G. et al. (2006). The toronto mindfulness scale: development and validation. Journal of Clinical Psychology, 62(12), 1445-1467. https://doi.org/10.1002/jclp.20326

Lindsay, E. K., \& Creswell, J. D. (2016). Mechanisms of mindfulness training: Monitor and Acceptance Theory (MAT). Clinical psychology review, 51, 48-59. https://doi.org/10.1016/j.cpr.2016.10.011

Masuda, A., \& Tully, E. C. (2012). The role of mindfulness and psychological flexibility in somatization, depression, anxiety, and general psychological distress in a nonclinical college sample. Journal of Evidence-Based Complementary and Alternative Medicine, 17, 66-71. https://doi.org/10.1177/2156587211423400

McAdams, D. P., \& de St. Aubin, E. D. (1992). A theory of generativity and its assessment through self report, behavioral acts, and narrative themes in autobiography. Journal of Personality and Social Psychology, 62, 1003-1015. https://doi.org/10.1037/0022-3514.62.6.1003

Patrick, C. J., Curtin, J. J., \& Tellegen, A. (2002). Development and validation of a brief form of the multidimensional personality questionnaire. Psychological Assessment, 14, 150-163. https://doi.org/10.1037/1040-3590.14.2.150

Pearlin, L. I., \& Schooler, C. (1978). The structure of coping. Journal of health and social behavior, 19, 2-21. https://doi.org/10.2307/2136319

Pepping, C. A., O'Donovan, A., \& Davis, P. J. (2013). The positive effects of mindfulness on self-esteem. The Journal of Positive Psychology, 8, 376-386. https://doi.org/10.1080/17439760.2013.807353

Prenda, K. M., \& Lachman, M. E. (2001). Planning for the future: A life management strategy for increasing control and life satisfaction in adulthood. Psychology and Aging, 16, 206-216. https://doi.org/10.1037/0882-7974.16.2.206

Roberts, K. C., \& Danoff-Burg, S. (2010). Mindfulness and health behaviors: Is paying attention good for you? Journal of American College Health, 59, 165-173. https://doi.org/10.1080/07448481.2010.484452

Roemer, L., Lee, J. K., Salters-Pedneault, K., Erisman, S. M., Orsillo, S. M., \& Mennin, D. S. (2009). Mindfulness and emotion regulation difficulties in generalized anxiety disorder: preliminary evidence for independent and overlapping contributions. Behavior Therapy, 40, 142-154. https://doi.org/10.1016/j.beth.2008.04.001

Rosenberg, M. (1965). Society and the adolescent self-image. Princeton, NJ: Princeton Univ. Press. https://doi.org/10.1515/9781400876136

Rossi, A. S. (2001). Caring and doing for others: Social responsibility in the domains of family, work, and community. Chicago, IL: University of Chicago Press.

Ruocco, A., \& Wonders, E. (2013). Delineating the contributions of sustained attention and working memory to individual differences in mindfulness. Personality and Individual Differences, 54, 226-230. https://doi.org/10.1016/j.paid.2012.08.037

Ryff, C. D. (1989). Happiness is everything, or is it? Explorations on the meaning of psychological wellbeing. Journal of Personality and Social Psychology, 57, 1069-1081. https://doi.org/10.1037/0022-3514.57.6.1069 
Scheier, M. F., \& Carver, C. S. (1985). Optimism, coping and health: Assessment and implications of generalized outcome expectancies. Health Psychology, 4, 219-247. https://doi.org/10.1037/0278-6133.4.3.219

Schuster, T. L., Kessler, R. C., \& Aseltine, R. H. (1990). Supportive interactions, negative interactions, and depressed mood. American Journal of Community Psychology, 18, 423-438. https://doi.org/10.1007/BF00938116

Segal Z. V., Williams J. M. G., \& Teasdale J. D. (2018). Mindfulness-based cognitive therapy for depression. New York: Guilford.

Sesker, A. A., Suilleabhain, P. O., Howard, S., \& Hughes, B. M. (2016). Conscientiousness and mindfulness in midlife coping: An assessment based on MIDUS II. Personality and Mental Health, 10, 29-42. https://doi.org/10.1002/pmh.1323

Singelis, T. M. (1994). The measurement of independent and interdependent self-construals. Personality and Social Psychology Bulletin, 20, 580-591. https://doi.org/10.1177/0146167294205014

Staudinger, U. M., Fleeson, W., \& Bates, P. B. (1999). Predictors of subjective physical health and global well-being: Similarities and differences between the United States and Germany. Journal of Personality and Social Psychology, 76, 305-319. https://doi.org/10.1037/0022-3514.76.2.305

Tellegen, A. (1985). Structure of mood and personality and their relevance to assessing anxiety, with an emphasis on self-report. In A. H. Tuma \& J. D. Maser (Eds.), Anxiety and the anxiety disorders (pp. 681-706). Hillsdale, NJ: Erlbaum. https://doi.org/10.4324/9780203728215-49

Uchida, Y., \& Kitayama, S. (2001). Development and validation of a sympathy scale. Japanese Journal of Psychology, 74, 275-282. https://doi.org/10.4992/jjpsy.72.275

Wallace, B. A. (2003). Introduction: Buddhism and science-breaking down the barriers. In B. A. Wallace (Ed.), Buddhism and science: Breaking new ground (pp. 1-30). New York: Columbia University Press.

Williams, J. M. G., \& Kabat-Zinn, J. (2011). Mindfulness: Diverse perspectives on its meaning, origins, and multiple applications at the intersection of science and dharma. Contemporary Buddhism, 12, 1-18. https://doi.org/10.1080/14639947.2011.564811

Zimmerman, M. A. (1995). Psychological empowerment: Issues and illustrations. American Journal of Community Psychology, 23, 581-599. https://doi.org/10.1007/BF02506983

\section{Copyrights}

Copyright for this article is retained by the author(s), with first publication rights granted to the journal.

This is an open-access article distributed under the terms and conditions of the Creative Commons Attribution license (http://creativecommons.org/licenses/by/4.0/). 